DOI: $10.20472 / E S .2020 .9 .2 .005$

\title{
HOW DO DIFFERENT FIRMS PERFORM WHILE TRADING OWN STOCK? A GRANULAR ANALYSIS ON SPECIFIC CHARACTERISTICS AND MARKET CONDITIONS
}

\author{
DINIS SANTOS, PAULO M. GAMA
}

\begin{abstract}
:
Which firms are more likely to time the market? This paper uses a relative transaction price approach, focusing on 37997 own stock transactions from Euronext Lisbon listed firms, ranging from 2005 to 2015, to estimate the relationship between the market timing ability of firms and a set of firm specific characteristics. Results show that smaller, more efficient but less valuable companies are more likely to be successful to time the market. Furthermore, we show that a shifting event such as a country bailout can lead to an increased performance from firms when trading own stock. Additionally, we find proof that OTC trading can be linked to lower market timing capabilities. At last, and due to the considerable weight of the financial sector within our sample, we estimated isolated results, which prove that the higher the relative performance of a firm when compared to its share value, the higher the capabilities of a financial sector firm to time the market when repurchasing own stock.
\end{abstract}

\section{Keywords:}

Repurchase, Resale, Own Stock, Opportunistic Behaviour, Market Timing, Own Stock Transaction Performance

JEL Classification: G14, G15

\section{Authors:}

DINIS SANTOS, Faculty of Economics, University of Coimbra, Portugal, Email: dinis.d.santos@fe.uc.pt PAULO M. GAMA, CeBER \& Faculty of Economics, University of Coimbra, Portugal, Email: gama@fe.uc.pt

\section{Citation:}

DINIS SANTOS, PAULO M. GAMA (2020). How do different firms perform while trading own stock? A granular analysis on specific characteristics and market conditions. International journal of Economic Sciences, Vol. IX(2), pp. 71-93., 10.20472/ES.2020.9.2.005 


\section{Introduction}

Achieving different results while trading own stock can be related to multiple factors. Characteristics such as dimension, financial performance, efficiency, valuation, and liquidity levels might be used to characterize firms, thus allowing explaining the different ability to time the market.

In this paper we use firm specific characteristics and relative transaction prices to derive which type of firms are more likely to time the market while trading own stock. We focus on characteristics such as dimension, financial performance, efficiency, valuation, and liquidity levels in order to estimate their impact on the firms' ability to time the market.

We make our contribution to the literature on market timing and own stock trading, in several ways. Firstly, we can prove the existence of different levels of market timing capabilities across firms with different characteristics. This is done by using both repurchasing and reselling activity from the same set of firms that trade at different frequency levels. By including both, repurchase and reselling operations, we detach from the published research. This because we do not tackle stock issuing, but already issued stock that is being re-sold. This provides a bilateral perspective. Furthermore, we include different benchmark periods across the study. These allow to investigate market timing from a past performance or future expectations perspectives.

Secondly, we make our contribute by studying both own stock trading in the open market and over the counter which has not been done for the same set of firms in a repurchase/reselling configuration. Here, we consider the fact that over the counter transactions go through a dealer network rather than through a centralized and formal exchange might result in performance differences on market timing. The reason for this is that the dealer directly connects buyers and sellers, creating asymmetries when comparing prices paid OTC and on open market.

As a complement to the study, we also study the impact of major economic shift on the firms trading capabilities. We include the Portuguese economic bailout ${ }^{1}$ of 2011 as a benchmark event in order to understand how such an event impacted on the firms trading capabilities when in pressure for funding. We believe that both the OTC and the macroeconomic shift components add to the literature on firms trading performance. Furthermore, the bailout component also contributes to the literature on corporate funding sourcing.

In order to provide these contributes, we focus on the Portuguese stock exchange listed firms, using data on 37997 transactions from 2005 to 2015 . Our dataset is of daily frequency and allows to establish the event-date and benchmark specific windows (with

\footnotetext{
${ }^{1}$ The bailout period can be identified as having started in April 2011 (Fernandes, Gama and Vieira, 2015).
} 
different lengths) in order to calculate the relative transaction prices such as in Santos and Gama (2019). The various intervals are designed to capture dissimilar trading activity with a higher or lower frequency.

Across our work, we use dummy variables to distinguish the firms trading frequency, to differentiate between open market and over the counter transactions, and to signalize the impact of the major macroeconomic event, in our case the 2011 bailout.

Furthermore, due to the major weight of the financial sector within the Euronext Lisbon stock exchange, we decided to create a sub-sample, isolating the financial sector only. Our main findings are as follows:

First, when analyzing the full range of transactions, we found that, smaller firms, with lower relative performance when compared to its share value, are better performers when trading own stock.

This is also true for firms with lower overall results. Still, improved market timing capabilities are also linked to higher levels of overall efficiency. This was proved true, both, when repurchasing and reselling own stock.

Second, and focusing on the bailout, it is important to state that in Portugal banks normally dominate the financial markets. Thus, firms tend to see bank credit as main source for financing and funding their operations and/or investments. However, during the bailout period, funding options were scarce as banks were not able to provide liquidity. This was a consequence of new regulation requirements implemented by the Troika, which included the European Commission (EC), the European Central Bank (ECB) and the International Monetary Fund (IMF), (Gurnani, 2011). Thus, when facing pressure, firms tend to search for flexible alternative sources for funding. This can generate a temporary bridge to a markets-based funding system.

Conventionally, economic systems where stock markets are the main funding source for firms are associated with a more long-term outlook (Demirgüç-Kunt and Maksimovic, 2012). However, in cases where there are no further funding sources available, trading own stock can also be used to fulfil short/medium necessities. Following this rationale, we bridge the 2011 bailout macroeconomic event with a markets-based funding system, where firms can actually use own stock trading as a practical funding option.

On this, our results show that after the 2011 bailout firms actually proved to be more efficient while trading own stock. Furthermore, infrequent traders (firms that trade at a lower frequency) were the ones showing higher market timing potential. Additionally, we show that OTC trading is linked to lower market timing capabilities.

Third, when we focus solely on the financial sector sub-sample, we find some dissimilarities from our previous results. More specifically, we find that the higher the relative performance of a firm when compared to its share value, the higher are its capabilities to time the market through repurchase operations. 
Fourth and final, we looked at forward looking relative transaction prices only. This allowed us to probe for the forecasting power of firms. Here, results prove similar for both the general and the financial data samples. Which suggests that no matter the characteristics of the firms, there was a homogeneous level of expectation regarding the stock market evolution.

The remaining of this paper is organized as follows. Section 2 presents the literature review of the most relevant studies. Section 3 describes the dataset, the data-collection process and computations as well as the regression model. Section 4 presents and discusses the empirical results. Section 5 concludes the paper.

\section{Literature review}

Market timing capabilities and firms' specific characteristics is not commonly covered across the literature. One exception to this, is the work of Dittmar and Field (2015). Here, the authors were able to prove there is a correlation between harder to value firms and higher market timing capabilities. They strongly focused on studying EPS forecasts across the firm panel.

On a parallel line, and also focusing EPS, Voss (2012) states that, when repurchasing stock, firms remove outstanding shares from the market, and this decreases the average shares outstanding that is the denominator used on the earnings per share indicator. Following the same logic, it is easy to understand that other metrics, i.e. the price to earnings ratio, are also affected by trading own stock. Such an activity might be used to increase the wealth of the remaining shareholders (Schneider \& Kohlmeyer, 2015).

As in any story, repurchasing stock has not only benefits but also less positive outcomes. Naturally, when repurchasing stock, firms have to own a superior or equal amount of cash in order to fulfil the needs to complete operation (Mintz, 2007), and this is not always easy to accomplish. Sometimes cash is limited, and even when it isn't, although repurchasing brings value in the short-term, that value replaces the investment in R\&D, new assets, human capital or other activities that could add value in the long run (Russolillo, 2014).

In the process of repurchasing stock, the firm would have to continuously be spending money coming from asset sales, borrowings or other sources, which similarly have limitations (Schneider \& Kohlmeyer, 2015). Furthermore, it is also known that, the literature presents evidence that by repurchasing, leverage ratios can be increased (Opler and Titman (1996) and Dittmar (2000)).

Additionally, and on a more operational note, we can easily assume that, on the limit, a firm can get to a place where it would not have any more shares to repurchase. Therefore, this cannot be looked as the only strategy to increase results, as it will not work forever.

With this, a question arises: is it better to repurchase or to invest in medium to long-term investments? 
This seems to be a hard question to answer, but:"...each dollar used to buy back a share is a dollar that is not spent on business activities that would otherwise stimulate economic growth." (Asness et al., 2018).

Thus, medium to long-term investments are retained in what can be called a myopic grassland. This is true for virtually all investment segments. Bending et al., 2017 paints a good picture on myopic marketing management, which is a specific version of this behavior.

One other aspect impacting on the decision to buy or sell own stock is the sheer management of a firm. As we previously discussed, repurchasing stock does increase some operational metrics by reducing the number of available shares in the open market. Thus, some management related factors such as performance-based compensation agreements may, in fact, be an element influencing own stock trading behavior and performance. This is, in fact, a setting that endangers the firm's health (Schneider \& Kohlmeyer, 2015).

From here, we deduce that there are many pros and cons of trading own stock. Also, firms that engage in these activities must consider multiple factors that range from a strategic to an operational perspective.

However, when we bucket the baseline theories regarding the motivation for trading own stock, we find that the research made in the last few decades basically follows three main theories. These are the insider trading option model (Vermaelen and Ikenberry, 1996), the free-cash-flow hypothesis (Jensen, 1986), and the market-signaling hypothesis (Vermaelen, 1981). Clearly, these research lines have evolved to accommodate new complexity levels. For instance, Jolls (1996), Fenn and Liang (1997), and Dittmar (2000) proposed that repurchasing helps firms to diminish the employees' stock options effects.

Furthermore, focusing on how firms perform while trading, recently, Fu and Cheng (2015) defend that due to a liquidity increase in the stock market, result of a decrease in the trading costs and the increase on the institutional investors seeking for new opportunities, long run abnormal returns related to repurchase transactions have been disappearing in the latest years.

With a such fast-evolving landscape, it seems fair to say that with information flowing faster now, one could think that there are no more information inefficiencies. However, this is not true, although speed is much higher, the volume of information available for investors is also much higher. Thus, markets can still be inefficient. Firms can still profit for over/undervaluation of their shares. See Kumar et al., (2017).

From an evolutionary perspective, thirty years ago, it was clear that there was an opportunity for profit if managers found their shares to be selling below their value (Buffet, 1984), and this was easy to measure as one would look for abnormal returns.

Nowadays, when analyzing the performance of a firm trading own stock, long run abnormal returns may not be the best measure due to its lack of benchmarking ability (Dittmar and 
Field 2015; Santos and Gama 2019). A better tool for evaluating market timing capabilities through trading own stock is the relative transaction price (RTP's), which was used introduced as relative repurchase price by Dittmar and Field (2015) and modified for higher frequency and broader application by Santos and Gama (2019).

Complementary, we believe the research in this field has evolved massively in the last years, however, there are still many areas for improving. For instance, trading own stock is more than just repurchasing. Reselling can also be used by firms and normally research is focused on stock issuing and repurchase operations only. In our view, analyzing market timing capabilities addressing both types of operations (repurchasing and reselling) can bring leveraged insights.

With this, it is fair to say that we complement the related literature by cross analyzing firm specific characteristics and relative prices to derive which type of firms are more likely to time the market with own stock trading. We cover buy and resell operations as well as trades made on the open market or OTC. Furthermore, we add to the current literature by including trading frequency and the impact of a major macroeconomic shifting event in the findings of our work.

\section{Research Design}

This section firstly introduces the available data as well as the necessary transformations such as the procedure to derive the relative transaction price, the frequency classification criteria, as well as the fundamental characteristics analyzed in the sample. After this, we present hour main hypothesis that arise from matching the literature review and the gathered \& processed data.

\subsection{Data collection}

In order to tackle firm specific characteristics and its links to the ability to time the market when trading own stock, we focused on the dataset introduced by Santos and Gama (2019). The corresponding sample comprises data on 821 individual disclosure documents, totaling for 33 firms (which comprises the full universe of firms which traded and reported within the analysis timeframe), with data ranging from January 2005 to March 2015 and accounting for 37997 transactions.

The documents were gathered from the $\mathrm{CMVM}^{1}$ and show original, unfiltered data uploaded by the firm itself. The number of disclosed documents and active trading firms on the market changes along the time spawn of the sample. According to Santos and Gama

\footnotetext{
${ }^{1}$ The Portuguese Securities Market Commission (CMVM), established in April 1991 focus on supervising and regulating securities and other financial instruments and the activity of all those interact within said markets. http://www.cmvm.pt/en/Pages/homepage.aspx
} 
(2019), firms are required to disclose in very specific conditions ${ }^{1}$ and these make our sample fitted to study own stock transactions with a high degree of reliability.

In order to deal with the high frequency of operations (intra-daily ${ }^{2}$ ), aggregation was done by computing the weighted average daily trade price. This was made separately for repurchase operations and resale operations in the open market, or over the counter ${ }^{3}$. Here, we followed the same approach as Santos and Gama (2019) (See annex I).

To address human error on disclosing, we filtered the data for outlier prices, misdating of operations as well as market opening incoherence regarding the stipulated trading calendar. We also readjusted all historical data to all capital events occurring from the disclosing date until the present analysis date. Capital change ${ }^{4}$ events with an adjustment factor different from zero were considered in this task. The outcome of this procedure was a robust dataset of 3740 aggregated daily observations for studying own stock transactions through repurchasing or reselling.

\subsection{Firm characteristics}

The behavior and performance while trading own stock is not constant between firms. Thus, to further try and understand these phenomena, we focused on analyzing firm specific characteristics and its impact on the market timing capabilities of firms while repurchasing or reselling stock.

For this, and in order to enhance the existing dataset, we gathered firm specific information proxying firm dimension, financial performance, efficiency, valuation, and liquidity levels, which, we believe have not been previously studied in the related literature.

To proxy for the previously stated dimensions we used the following variables ${ }^{5}$ : the market capitalization for dimension, the return on assets for efficiency, EBITDA and the basic earnings per share excluding extraordinary items for financial performance, the price to

\footnotetext{
${ }^{1}$ Quoting the CMVM regulation Section II of the n. ${ }^{\circ}$ 5/2008: Own shares transactions are required to be disclosed when: The cumulative value of own shares transactions adds up to $1 \%$ or successive multiples of the total nominal value of their shares (calculated since the last effective disclosure), or if in the same market session, the amount of transacted stock is higher than $0.05 \%$ of the total firm traded shares. Disclosing information must be done within three days counting from the respective date on which there was a transgression of one of the thresholds. Other countries in Europe follow a slightly different approach (Drousia et al., 2016)

${ }^{2}$ Original PDF files can disclose trading data trade-by-trade (high frequency), or daily aggregated, or even aggregated by order (which may be executed in several different trades). Aggregating data daily allows for comparing all different scenarios.

${ }^{3}$ PHP programing (Hypertext Preprocessor) was used to process the aggregation tasks more efficiently.

${ }^{4}$ Capital change data was retrieved from Thompson Reuters Eikon

${ }^{5}$ Data was retrieved from Thompson Reuters.
} 
earnings for relative valuation, quick ratio for liquidity and finally the total shareholder's equity for overall financial health.

Having gathered and proxied our study dimensions, we ended up with an unbalanced panel dataset which would allow to characterize firms according to their market timing abilities.

\subsection{Relative transaction price and frequency status}

The Relative Transaction Prices (or RTP) approach, as in Santos and Gama (2019), focus on comparing the average repurchase prices (average resale price) paid (received) by a firm in the course of a specific period, the trade price (TP), and a pre-defined benchmark, the benchmark price (BP).

Following the methodology used in the calculation of the average daily trade price, we use daily frequency data to compute trade prices for 5-day, 22-day and 66-day length time windows (both centered and forward looking) in order to compute the benchmark prices.

Thus, because the RTP always compares the own stock trading price to a benchmark. This ratio signal allows to assess the performance of firms when trading own stock.

On one hand, when the trade price is insignificantly different from the benchmark price, the firm shows neutral performance. On the other hand, if there are statistically significant differences between the average trade price and the benchmark price, which may be negative or positive, we assume that firms perform better (worse) than other traders, making them able (unable) to time the market. For a more specific methodology on the calculation of the Relative Transaction Prices please see annex I-B.

Regarding the frequency on which firms trade own stock, we may say that the trading activity among the firms within the sample is not homogeneous. This is expected to influence the traders timing skills and consequently the results of firms while trading own stock.

There are two distinct points of view when looking at this issue. Firstly, there is the perspective were a lower own stock trading frequency may be associated with lack of experience, therefore linked to a lower capacity of market timing. Secondly, there is the perspective where a higher trading frequency can lead the market to learn the patterns of a firm trading own stock at a high frequency rate. Thus, reducing the market timing capabilities. Going even further, we can also defend that the higher the trading frequency the smaller the time windows to obtain good results.

Therefore, using the same approach as in Santos and Gama (2019), we use a three-layer classification system for trading frequency. We classify firms as frequent, moderate or infrequent traders. Here, we took a specific approach looking at the typical trading days per year (255 days) in the Portuguese market (Euronext Lisbon). 
So, for each year in the sample, we consider a frequent trader a firm that trades in more than $15 \%$ of the normal year trading days, a moderate trader as a firm that trades in more than $5 \%$ of the normal year trading days but in less than $15 \%$ of the typical year trading days, and finally, we consider an infrequent trader a firm trading in less than $5 \%$ of the normal years trading days ${ }^{1}$.

\subsection{Relative Transaction Price sample description}

Regarding the relative transaction prices, table 1 presents a brief description of our sample. Totaling 3740 aggregated daily observations, we account from four distinct types of transactions.

Overall, we present data on 2839 repurchase transactions. Where 2730 took place on the open market and 109 over the counter. Focusing on resales transactions, we present data on 899 transactions from which 591 were made on the open market and 308 over the counter.

Table 1: Sample description

\begin{tabular}{|c|c|c|c|c|c|c|c|c|}
\hline \multirow[t]{2}{*}{ Year } & \multicolumn{2}{|c|}{ Transactions (daily) } & \multicolumn{2}{|c|}{ Market } & \multicolumn{4}{|c|}{ Firms trading own stock } \\
\hline & Repurchase & Resales & Open Market & OTC & $\mathrm{N}$ & $\begin{array}{c}\text { Frequent } \\
\%\end{array}$ & $\begin{array}{c}\text { Moderate } \\
\%\end{array}$ & $\begin{array}{c}\text { Infrequent } \\
\%\end{array}$ \\
\hline 2005 & 282 & 139 & 289 & 132 & 26 & $25.00 \%$ & $8.33 \%$ & $66.67 \%$ \\
\hline 2006 & 185 & 209 & 304 & 90 & 26 & $25.00 \%$ & $16.67 \%$ & $58.33 \%$ \\
\hline 2007 & 218 & 193 & 312 & 99 & 29 & $21.43 \%$ & $14.29 \%$ & $64.29 \%$ \\
\hline 2008 & 421 & 93 & 456 & 58 & 28 & $33.33 \%$ & $26.67 \%$ & $40.00 \%$ \\
\hline 2009 & 268 & 33 & 290 & 11 & 28 & $21.43 \%$ & $21.43 \%$ & $57.14 \%$ \\
\hline 2010 & 215 & 41 & 253 & 3 & 28 & $18.18 \%$ & $36.36 \%$ & $45.45 \%$ \\
\hline 2011 & 646 & 122 & 766 & 2 & 27 & $38.46 \%$ & $7.69 \%$ & $53.85 \%$ \\
\hline 2012 & 256 & 9 & 257 & 8 & 27 & $18.18 \%$ & $54.55 \%$ & $27.27 \%$ \\
\hline 2013 & 47 & 6 & 52 & 1 & 29 & $0.00 \%$ & $14.29 \%$ & $85.71 \%$ \\
\hline 2014 & 183 & 52 & 225 & 10 & 29 & $9.09 \%$ & $36.36 \%$ & $54.55 \%$ \\
\hline 2015 & 118 & 2 & 117 & 3 & 29 & $25.00 \%$ & $0.00 \%$ & $75.00 \%$ \\
\hline Total & 2839 & 899 & 3321 & 417 & & & & \\
\hline
\end{tabular}

\footnotetext{
${ }^{1}$ In our system the frequency status is calculated in a yearly basis. Thus, one firm may have different frequency status in different years within the sample.
} 
This table presents the number of observations after daily aggregation available for each year between 2005 and 2015, regarding all the distinct types of transactions; Repurchases, and Resales, as well as segmentation by market type (Open Market vs Over the Counter).

It also presents the number of firms that traded in each year and the \% distribution of firms classified as Infrequent, moderate and frequent by each year. This classification is based on the daily transaction count over the total transaction days available in each year. Firms that transacted in less than $5 \%$ of all available transaction days are considered infrequent traders, the ones that transacted in between $5 \%$ and $15 \%$ of the total available transition days are considered moderate traders, and finally the ones that transacted in more than $15 \%$ of all the transaction days are considered frequent traders.

Regarding the frequency status of the firms, the frequency distribution as a percentage of the total firms that traded in each year of the sample shows that we have a larger group of infrequent traders. The second largest group are the moderate traders and at last the frequent traders' group.

Noticeably, in 2012 this is not true as moderate traders are the largest group within the sample (they accounted for more than $54 \%$ of the total trading firms).

\subsection{Modelling}

When testing the RTP's ability to be used as dependent variable, we found that the sample did not follow a normal distribution ${ }^{1}$ (see table 2, which presents the mean and median RTP results). Therefore, this supported our decision to the median value as a measure for comparing performance throughout the remaining of this work.

To identify relationships linking firms' specific characteristics and the ability to time the market, we estimated a set of pooled regressions on the medians using the RTP's as dependent variables and the firm characteristics as regressors.

Overall, and covering the full sample, we applied the natural logarithm to all data that was not being presented in percentage or ratio form. This was made for scaling and interpretation purposes.

Accordingly, we also introduced set of dummy variables to account for the bailout period, the frequency status of the firm and to account for transactions made over the counter. This was made separately for repurchase and resell operations. Thus, the complete model is computed as follows:

\footnotetext{
${ }^{1}$ We use the Shapiro -Wilk W test for normality to the different RTP's samples. This is done since, a priori, we do not know the distribution pattern of the relative transaction prices. The Shapiro-Wilk test is a test of normality in frequentist statistics. Published in 1965 by Samuel Sanford Shapiro and Martin Wilk it is commonly used to test series follows or not a normal distribution.
} 


$$
\begin{gathered}
R T P_{i t}=\alpha+\beta_{1} \text { basicEPS }_{i t}+\beta_{2} P E_{i t}+\beta_{3} R_{O A A_{i t}}+\beta_{4} \text { LnEBITDA }_{i t}+\beta_{5} \text { quickratio }_{i t}+ \\
\beta_{6} \text { Lntotalequity }_{i t}+
\end{gathered}
$$

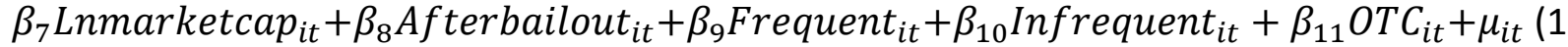

Where, $R T P_{i t}$ - Stands for the Relative Transaction Price for each benchmark; $\alpha$ - is the model constant; $\beta_{n}$ - is the coefficient coming from the respective regressor; the specific regressors; Afterbailout is a dummy variable turning 1 if the transaction is made after the bailout; Frequent is a dummy variable turning 1 if the transaction is made by firms which are classified as frequent traders and 0 otherwise; Infrequent is a dummy variable turning 1 if the transaction is made by firms which are classified as infrequent and 0 otherwise and; OTC is a dummy variable turning 1 if the transaction is made over the counter and $\mu_{i t}$ is the error term.

In this model, increases in the market timing capabilities are measured in negative (positive) impacts on the repurchase (resell) related RTP's.

\subsection{Formulating our base hypothesis}

As previously discussed, the aim of this work is to we use firm specific characteristics and relative transaction prices to infer on which type of firms are more likely to time the market while trading own stock.

Along with the more general objective we formulated several hypotheses to help structuring some (but not limited) of our findings.

- H1: Different firms with different characteristics will showcase different levels of market timing capabilities on both their repurchasing and reselling activity.

This provides a bilateral perspective. Note that we include different benchmark periods across the study. These allow to investigate market timing from a past performance or future expectations perspectives.

- H2: Smaller firms will be able to perform better while trading own stock.

The support for this hypothesis comes from the fact that normally, smaller firms are under less scrutiny. On the contrary larger firms are under the spotlight with a higher number of analyst followers which monitor every event and transaction thus reducing the room for timing the market.

- H3: Infrequent traders will outperform other firms while timing the market while trading own stock.

The base for this hypothesis is that first of all, infrequent traders have higher trading windows to time their actions, But more than that, as there is less historical learnings from the traders, other market players are not able to anticipate or predict their moves as well. 
- H4: Trading over the counter provides a better set-up for firms to time the market.

This hypothesis is based on the fact that over the counter transactions go through a dealer network rather than through a centralized and formal exchange. Like so, performance differences on market timing are expected. This is driven by the dealer directly connecting buyers and sellers, creating asymmetries when benchmarking transaction on open market.

We also aim to infer on the impact of the Portuguese bailout on the trading capabilities, as well as differences in between Financial sector firms as they comprise a large percentage of the Euronext Lisbon. Furthermore, we will explore the effects on forward looking relative transaction prices in order to assess the forecasting power of firms.

\section{Empirical results and discussion}

In this section, we present the results of the computed regressions for both operation types (repurchase and resell). We focus both on the full sample analysis as well as our financial sector sub-sample. We also address the differential RTP mechanics by analysis centered RTPs (-5 to $5,-22$ to $22,-66$ to 66 ) or forward looking RTPs (0 to 5,0 to 22,0 to 66 ).

\subsection{Full sample centered RTP's}

Regarding our general sample, table 2 shows the results of the estimations including both repurchase and resell operations. Here, we find that indeed, some firm specific characteristics do influence the market timing capabilities.

Table 2: General Repurchase vs. Resell centered benchmarks

\begin{tabular}{|c|c|c|c|c|c|c|}
\hline & \multicolumn{3}{|c|}{ Panel A: Repurchase Activity } & \multicolumn{3}{|c|}{ Panel B: Resell Activity } \\
\hline & RTP -66 to 66 & RTP -22 to 22 & RTP -5 to 5 & RTP -66 to 66 & RTP -22 to 22 & RTP -5 to 5 \\
\hline \multirow{2}{*}{$\begin{array}{l}\text { Basic EPS } \\
\text { excluding } \\
\text { extraordinary } \\
\text { items }\end{array}$} & 0.2045196 & 0.072787 & 0.0102901 & -0.6227766 & -0.8505015 & 0.2197113 \\
\hline & $(0.000 * * *)$ & $(0.007 * * *)$ & $(0.240)$ & $(0.000 * * *)$ & $(0.000 * * *)$ & $(0.003 * * *)$ \\
\hline \multirow{2}{*}{ Price-to-Earnings } & $2.16 \mathrm{e}-07$ & $7.03 e-06$ & $1.77 \mathrm{e}-06$ & 0.000018 & $6.20 \mathrm{e}-06$ & $-3.35 e-06$ \\
\hline & $(0.966)$ & $(0.060 *)$ & $(0.171)$ & $(0.062 *)$ & $(0.314)$ & $(0.465)$ \\
\hline \multirow{2}{*}{ Return-on-Assets } & -0.027164 & -0.0090026 & -0.002288 & 0.0288902 & 0.0568157 & 0.0222056 \\
\hline & $(0.000 * * *)$ & $(0.001 * * *)$ & $(0.014 * *)$ & $(0.028 * *)$ & $(0.000 * * *)$ & $(0.001 * * *)$ \\
\hline \multirow{2}{*}{ EBITDA } & 0.0003531 & 0.0001396 & 0.0001378 & 0.0001741 & 0.0000186 & 0.0001079 \\
\hline & $(0.002 * * *)$ & $(0.104)$ & $(0.000 * * *)$ & $(0.563)$ & $(0.922)$ & $(0.480)$ \\
\hline Quick Ratio & -0.0003118 & -0.0011065 & 0.0001098 & 0.0005093 & 0.0003412 & 0.0003419 \\
\hline
\end{tabular}




\begin{tabular}{|c|c|c|c|c|c|c|}
\hline & $(0.013 * *)$ & $(0.000 * * *)$ & $(0.000 * * *)$ & $\left(0.000^{* * *}\right)$ & $\left(0.000^{* * *}\right)$ & $(0.000 * * *)$ \\
\hline \multirow{2}{*}{$\begin{array}{l}\text { Total } \\
\text { Shareholders' } \\
\text { Equity }\end{array}$} & -0.0179541 & -0.0071733 & -0.001676 & -0.0121052 & 0.0034414 & 0.0008998 \\
\hline & $(0.000 * * *)$ & $(0.000 * * *)$ & $(0.006 * * *)$ & $(0.063 *)$ & $(0.411)$ & $(0.766)$ \\
\hline \multirow{2}{*}{$\begin{array}{l}\text { Market } \\
\text { Capitalization }\end{array}$} & 0.0194132 & 0.0065934 & 0.0002562 & -0.0066656 & -0.0045829 & -0.0052238 \\
\hline & $\left(0.000^{* * *}\right)$ & $(0.001 * * *)$ & $(0.700)$ & $(0.391)$ & $(0.356)$ & $(0.166)$ \\
\hline \multirow{2}{*}{ Over the Counter } & 0.0243548 & 0.0196624 & 0.0019859 & 0.1062473 & 0.0002057 & 0.0245881 \\
\hline & $(0.041)$ & $\left(0.025^{* *}\right)$ & $(0.493)$ & $\left(0.000^{* * *}\right)$ & $(0.977)$ & $(0.000 * * *)$ \\
\hline \multirow{2}{*}{ After Bailout } & -0.0277898 & -0.0059132 & 0.0001026 & 0.0012655 & 0.001682 & 0.0039291 \\
\hline & $(0.000 * * *)$ & $\left(0.013^{*}\right)$ & $(0.895)$ & $(0.866)$ & $(0.720)$ & $(0.266)$ \\
\hline$\overline{\text { Pseudo } R^{\wedge} 2}$ & 0.0444 & -0.0046 & 0.0060 & 0.0117 & 0.0693 & $(0.0547$ \\
\hline
\end{tabular}

This table presents in Panel A (Panel B) the median regressions for the repurchase (resell) operations over the chosen characteristics within the sample. The aim of the estimation is to define evidence of specific fundamental characteristics linked to own stock transaction performance. RTP stands for Relative Transaction Price and -5 to 5, -22 to 22, -66 to 66, stands for the time interval of the benchmark used in the calculation giving us forward looking relative transaction prices. Heteroskedasticity and autocorrelation robust standard errors are used. ${ }^{* * * * *}$ and ${ }^{*}$ show statistical significance at a level of 1, 5 and $10 \%$ respectively.

For instance, when looking at the Basic EPS excluding extraordinary items, our results show a positive impact on repurchase related RTP's, thus firms with a higher EPS ratio repurchase at a relatively higher price. We also show a negative impact on the resales related RTP's. Thus, firms with higher EPS ratios tend to resell own stock at a relatively lower price. Both these results suggest that the higher the relative performance of a firm when compared to its share value, the lower the capabilities of a firm to time the market. This is true for both repurchasing and reselling.

The same type of impact comes from the EBITDA and the Market capitalization variables which proxy performance and firm size. However, both these indicators only prove to be statistically significant results when looking at repurchasing operations.

Contrarily to the latter, we find that firms with a higher ROA, thus higher efficiency, seem to have better timing market capabilities both when repurchasing and when reselling own stock. We also find that this effect is stronger when the analysis interval is larger.

Furthermore, both the quick ratio and the total shareholders' equity, proxies for liquidity and overall financial health, show mixed results. In the case or repurchase operations, firms with higher indicators show stronger market timing capabilities. On the contrary, these capabilities are weaker when reselling. 
Moreover, the results regarding price-to-earnings ratio, proxy for relative valuation, were the ones showing a lower degree of statistical significance across the board. Overall, they show a very small effect on the capabilities to time the market measured by the RTP's. This effect is positive when reselling (positive signal) and negative when repurchasing (positive signal)

Regarding our dummy variables, repurchase transactions made after the bailout proved to be more likely to outperform the market. Here, infrequent traders where the ones achieving better results both when repurchasing and when reselling, which might be linked to the fact that they have more time to plan their trades and that they third party investors do not have so much historical information about their trades to predict their behavior.

At last, when looking at over the counter transactions, these proved to be inefficient for firms showing inferior results when repurchasing own stock and mixed results depending on the analysis timeframe when reselling.

\subsection{Financial sector centered RTP's}

When addressing our financial sector subsample, we only analyzed repurchase operations as the resell information proved to be non-significant, shown on table 3 . Here, we find nonsimilar results coming from our regression analysis.

Table 3: Financial sector Repurchase

\begin{tabular}{|c|c|c|c|}
\hline \multicolumn{4}{|l|}{ Panel A: Repurchase Activity } \\
\hline & RTP -66 to 66 & RTP -22 to 22 & RTP -5 to 5 \\
\hline \multirow[t]{2}{*}{ Basic EPS excluding extraordinary items } & -21.28488 & -18.72814 & -21.94958 \\
\hline & $(0.000 * * *)$ & $(0.000 * * *)$ & $(0.000 * * *)$ \\
\hline \multirow[t]{2}{*}{ Price-to-Earnings } & 0.0000344 & -0.000022 & -0.0000853 \\
\hline & $(0.160)$ & $(0.907)$ & $(0.162)$ \\
\hline \multirow[t]{2}{*}{ Return-on-Assets } & 1.557995 & 1.292925 & 1.427235 \\
\hline & $(0.000 * * *)$ & $(0.000 * * *)$ & $(0.000 * * *)$ \\
\hline \multirow[t]{2}{*}{ EBITDA } & -0.0443557 & 0.0328232 & 0.0045493 \\
\hline & $(0.000 * * *)$ & $(0.002 * * *)$ & $(0.131)$ \\
\hline \multirow[t]{2}{*}{ Quick Ratio } & 2.862935 & -1.980076 & -0.3456805 \\
\hline & $(0.000 * * *)$ & $(0.002 * * *)$ & $(0.060 * *)$ \\
\hline \multirow[t]{2}{*}{ Total Shareholders' Equity } & -2.990231 & 1.659043 & 0.1223821 \\
\hline & $(0.000 * * *)$ & $(0.009 * * *)$ & $(0.499)$ \\
\hline
\end{tabular}




\begin{tabular}{llll}
\hline Market Capitalization & 1.025893 & -0.0912211 & 0.0847377 \\
& $\left(0.000^{* * *}\right)$ & $(0.375)$ & $\left(0.012^{* *}\right)$ \\
\hline Over the Counter & -0.074727 & -0.0031153 & 0.0253408 \\
& $\left(0.000^{* * *}\right)$ & $(0.861)$ & $\left(0.000^{* * *}\right)$ \\
\hline After Bailout & N/A & N/A & N/A \\
\hline Frequent & N/A & N/A & N/A \\
\hline Infrequent & -0.3881409 & 0.1619659 & -0.0884894 \\
& $\left(0.000^{* * *}\right)$ & $(0.016 * *)$ & $(0.000 * * *)$ \\
\hline Const & 30.24068 & -24.49031 & -3.100042 \\
& $\left(0.000^{* * *}\right)$ & $(0.003 * * *)$ & $(0.194)$ \\
\hline Pseudo R^2 & 0.5367 & 0.4538 & 0.4184 \\
\hline
\end{tabular}

This table presents in Panel $A$ the median regressions for the repurchase operations of financial firms over the chosen characteristics within the sample. The aim of the estimation is to define evidence of specific fundamental characteristics linked to own stock transaction performance. RTP stands for Relative Transaction Price and -5 to $5,-22$ to $22,-66$ to 66 , stands for the time interval of the benchmark used in the calculation giving us forward looking relative transaction prices. Heteroskedasticity and autocorrelation robust standard errors are used. ${ }^{* * * * *}$ and ${ }^{*}$ show statistical significance at a level of 1,5 and $10 \%$ respectively.

First, the Basic EPS excluding extraordinary items, has a high negative impact on the repurchase related RTP's, thus firms with a higher EPS ratio repurchase at a relatively lower price. This suggests that the higher the relative performance of a firm when compared to its share value, the higher the capabilities of a firm from the financial sector to time the market through repurchases.

In this case, because the Portuguese stock exchange related data is mainly comprised of transactions from banks, we see that banks EPS have a high correlation with their market timing capabilities.

Second, the market capitalization, which proxy firm size, shows again a contrary signal. Suggesting that bigger banks have more trouble on timing the market while repurchasing.

Third, when looking at the remaining variables, we find that they show mixed results depending on the timeframe of the analysis.

Regarding our dummy variables, we confirm that infrequent traders are the ones achieving better results even when looking at our financial sector subsample. However, an exception 
comes from the monthly RTP's regression which proves that both back testing and future expectations management play an important role on market timing capabilities.

\subsection{Forward looking RTP's}

Aiming to pressure test the forecasting capabilities of firms, we focused solely on forward looking RTPs (see table 4), here, results proved to be in line with our centered RTP's approach. However, due to sample size differences, the levels of statistical significance slightly differ.

Table 4: General Repurchase vs. Resell Forward looking benchmarks

\begin{tabular}{|c|c|c|c|c|c|c|}
\hline & \multicolumn{3}{|c|}{ Panel A: Repurchase Activity } & \multicolumn{3}{|c|}{ Panel B: Resell Activity } \\
\hline & RTP 0 to 66 & RTP 0 to 22 & RTP 0 to 5 & RTP 0 to 66 & RTP 0 to 22 & RTP 0 to 5 \\
\hline $\begin{array}{l}\text { Basic EPS } \\
\text { excluding } \\
\text { extraordinary } \\
\text { items }\end{array}$ & $\begin{array}{l}0.3583774 \\
(0.000 * * *)\end{array}$ & $\begin{array}{l}0.0700066 \\
(0.008 * * *)\end{array}$ & $\begin{array}{c}-0.0129982 \\
(0.234)\end{array}$ & $\begin{array}{c}-0.2742167 \\
(0.358)\end{array}$ & $\begin{array}{l}-0.891795 \\
(0.000 * * *)\end{array}$ & $\begin{array}{c}0.012728 \\
(0.904)\end{array}$ \\
\hline $\begin{array}{l}\text { Price-to- } \\
\text { Earnings }\end{array}$ & $\begin{array}{c}1.21 \mathrm{e}-06 \\
(0.835)\end{array}$ & $\begin{array}{c}-4.85 \mathrm{e}-07 \\
(0.901)\end{array}$ & $\begin{array}{c}-2.90 \mathrm{e}-06 \\
\left(0.060^{*}\right)\end{array}$ & $\begin{array}{c}-0.0000241 \\
(0.199)\end{array}$ & $\begin{array}{c}-1.85 \mathrm{e}-06 \\
(0.823)\end{array}$ & $\begin{array}{c}3.37 \mathrm{e}-06 \\
(0.609)\end{array}$ \\
\hline $\begin{array}{l}\text { Return-on- } \\
\text { Assets }\end{array}$ & $\begin{array}{l}-0.0494993 \\
(0.000 * * *)\end{array}$ & $\begin{array}{l}-0.010928 \\
(0.000 * * *)\end{array}$ & $\begin{array}{c}-0.0006465 \\
(0.576)\end{array}$ & $\begin{array}{c}.0159482 \\
(0.560)\end{array}$ & $\begin{array}{l}0.1683041 \\
\left(0.000^{* * *}\right)\end{array}$ & $\begin{array}{c}-0.0078732 \\
(0.414)\end{array}$ \\
\hline EBITDA & $\begin{array}{c}-0.0002068 \\
(0.103)\end{array}$ & $\begin{array}{l}0.0003456 \\
(0.000 * * *)\end{array}$ & $\begin{array}{l}0.0001732 \\
(0.000 * * *)\end{array}$ & $\begin{array}{c}-0.0012011 \\
(0.048 * *)\end{array}$ & $\begin{array}{l}-0.0015743 \\
\left(0.000^{* * *}\right)\end{array}$ & $\begin{array}{c}-.0003096 \\
(0.132)\end{array}$ \\
\hline Quick Ratio & $\begin{array}{l}-0.000552 \\
(0.000 * * *)\end{array}$ & $\begin{array}{c}-0.0001215 \\
(0.184)\end{array}$ & $\begin{array}{c}-0.0000661 \\
(0.081 *)\end{array}$ & $\begin{array}{l}-0.0004487 \\
(0.000 * * *)\end{array}$ & $\begin{array}{l}-0.0004095 \\
(0.000 * * *)\end{array}$ & $\begin{array}{l}-0.0003088 \\
\left(0.000^{* * *}\right)\end{array}$ \\
\hline $\begin{array}{l}\text { Total } \\
\text { Shareholders' } \\
\text { Equity }\end{array}$ & $\begin{array}{l}-0.0211213 \\
(0.000 * * *)\end{array}$ & $\begin{array}{c}-0.0039406 \\
(0.034 * *)\end{array}$ & $\begin{array}{l}-0.0031846 \\
(0.000 * * *)\end{array}$ & $\begin{array}{c}-0.0172275 \\
(0.176)\end{array}$ & $\begin{array}{l}-0.0485241 \\
(0.000 * * *)\end{array}$ & $\begin{array}{l}0.0093224 \\
\left(0.035^{* *}\right)\end{array}$ \\
\hline $\begin{array}{l}\text { Market } \\
\text { Capitalization }\end{array}$ & $\begin{array}{l}0.0363823 \\
(0.000 * * *)\end{array}$ & $\begin{array}{c}0.0031012 \\
(0.124)\end{array}$ & $\begin{array}{c}0.0015619 \\
(0.061 *)\end{array}$ & $\begin{array}{l}0.0434764 \\
\left(0.005^{* * *}\right)\end{array}$ & $\begin{array}{l}0.0447171 \\
\left(0.000^{* * *}\right)\end{array}$ & $\begin{array}{c}-0.0100263 \\
(0.061 *)\end{array}$ \\
\hline $\begin{array}{l}\text { Over the } \\
\text { Counter }\end{array}$ & $\begin{array}{c}0.0252633 \\
(0.050 *)\end{array}$ & $\begin{array}{l}0.0258344 \\
(0.003 * * *)\end{array}$ & $\begin{array}{l}0.0151061 \\
(0.000 * * *)\end{array}$ & $\begin{array}{c}-0.0069723 \\
(0.743)\end{array}$ & $\begin{array}{c}-0.0126947 \\
(0.192)\end{array}$ & $\begin{array}{l}-0.0491742 \\
\left(0.000^{* * *}\right)\end{array}$ \\
\hline After Bailout & $\begin{array}{l}-0.0211965 \\
(0.000 * * *)\end{array}$ & $\begin{array}{l}-0.005664 \\
(0.017 * *)\end{array}$ & $\begin{array}{l}-0.0028356 \\
(0.004 * * *)\end{array}$ & $\begin{array}{c}0.0051432 \\
(0.721)\end{array}$ & $\begin{array}{l}-0.0198869 \\
(0.002 * * *)\end{array}$ & $\begin{array}{c}-0.0005703 \\
(0.910)\end{array}$ \\
\hline Frequent & $\begin{array}{l}0.0190268 \\
(0.000 * * *)\end{array}$ & $\begin{array}{c}0.0022569 \\
(0.407)\end{array}$ & $\begin{array}{c}0.0017401 \\
(0.123)\end{array}$ & $\begin{array}{l}0.0894796 \\
(0.001 * * *)\end{array}$ & $\begin{array}{l}0.0929754 \\
(0.000 * * *)\end{array}$ & $\begin{array}{l}-0.0259096 \\
\left(0.006^{* * *}\right)\end{array}$ \\
\hline
\end{tabular}




\begin{tabular}{lcccccc}
\hline Infrequent & 0.0190268 & -0.0093941 & -0.0098817 & .0582623 & -0.0892603 & 0.007658 \\
& $(0.000 * * *)$ & $(0.039 * *)$ & $(0.000 * * *)$ & $(0.017 * * *)$ & $(0.000 * * *)$ & $(0.377)$ \\
\hline Const & -0.278015 & 0.0125753 & 0.0278181 & -0.5496243 & 0.031079 & 0.0353218 \\
& $(0.000 * * *)$ & $(0.559)$ & $(0.002 * * *)$ & $(0.001 * * *)$ & $(0.641)$ & $(0.515)$ \\
\hline Pseudo R`2 & 0.0635 & 0.0181 & 0.0007 & 0.0370 & 0.0182 & 0.0404
\end{tabular}

This table presents in Panel A (Panel B) the median regressions for the repurchase (resell) operations over the chosen characteristics within the sample. The aim of the estimation is to define evidence of specific fundamental characteristics linked to own stock transaction performance. RTP stands for Relative Transaction Price and -5 to 5, -22 to 22, -66 to 66, stands for the time interval of the benchmark used in the calculation giving us forward looking relative transaction prices. Heteroskedasticity and autocorrelation robust standard errors are used. ${ }^{* * *, * *}$ and ${ }^{*}$ show statistical significance at a level of 1,5 and $10 \%$ respectively.

Our regression coefficient signals for the fundamental characteristics of firms coincide across the board with a one exception. This exception is the market capitalization variable, which now shows statistically significant results for reselling operations. Although significant, these results are mixed and correlated to an increase on the RTP time frame from weekly to monthly and then to quarterly.

Furthermore, our proxy for relative valuation (Price-to-earnings) shows inverse results when compared tour previous approach. Again, we do find a very small impact, but nonetheless a positive impact on the market timing capabilities when repurchasing own stock and a negative impact when reselling.

Regarding our dummy variables, and addressing forward-looking RTP's only, it is even clearer that OTC operations reduce the market timing capabilities of firms both when repurchasing and reselling. This is given by positive (negative) coefficients in the repurchase (resell) related regressions.

Repurchasing after the bailout also proved to be more advantageous for firms, and finally, according to the forward looking RTP's regressions, infrequent traders are the ones obtaining the best results when repurchasing, but, now, frequent traders obtain higher results when reselling (this can be interpreted by the positive, and higher, coefficients of the frequent dummy in our reselling related regressions). This result can be related to a learning process of trading own stock and managing future expectations. More experienced firms may indeed be better are forecasting.

On a final remark, regarding our financial sector specific results accounting only for forward looking RTP's (see table 5), results proved the same as in the centered RTP's regressions but stronger. 
Table 5: Financial sector Repurchase (forward looking only)

\begin{tabular}{|c|c|c|c|}
\hline \multicolumn{4}{|l|}{ Panel A: Repurchase Activity } \\
\hline & RTP -66 to 66 & RTP -22 to 22 & RTP -5 to 5 \\
\hline \multirow[t]{2}{*}{ Basic EPS excluding extraordinary items } & -21.28488 & -18.72814 & -21.94958 \\
\hline & $\left(0.000^{* * *}\right)$ & $(0.000 * * *)$ & $(0.000 * * *)$ \\
\hline \multirow[t]{2}{*}{ Price-to-Earnings } & 0.0000344 & -0.000022 & -0.0000853 \\
\hline & $(0.160)$ & $(0.907)$ & $(0.162)$ \\
\hline \multirow[t]{2}{*}{ Return-on-Assets } & 1.557995 & 1.292925 & 1.427235 \\
\hline & $(0.000 * * *)$ & $(0.000 * * *)$ & $\left(0.000^{* * *}\right)$ \\
\hline \multirow[t]{2}{*}{ EBITDA } & -0.0443557 & 0.0328232 & 0.0045493 \\
\hline & $(0.000 * * *)$ & $(0.002 * * *)$ & $(0.131)$ \\
\hline \multirow[t]{2}{*}{ Quick Ratio } & 2.862935 & -1.980076 & -0.3456805 \\
\hline & $(0.000 * * *)$ & $(0.002 * * *)$ & $\left(0.060^{* *}\right)$ \\
\hline \multirow[t]{2}{*}{ Total Shareholders' Equity } & -2.990231 & 1.659043 & 0.1223821 \\
\hline & $(0.000 * * *)$ & $(0.009 * * *)$ & $(0.499)$ \\
\hline \multirow[t]{2}{*}{ Market Capitalization } & 1.025893 & -0.0912211 & 0.0847377 \\
\hline & $(0.000 * * *)$ & $(0.375)$ & $(0.012 * *)$ \\
\hline \multirow[t]{2}{*}{ Over the Counter } & -0.074727 & -0.0031153 & 0.0253408 \\
\hline & $(0.000 * * *)$ & $(0.861)$ & $\left(0.000^{* * *}\right)$ \\
\hline After Bailout & N/A & N/A & N/A \\
\hline Frequent & N/A & N/A & N/A \\
\hline \multirow[t]{2}{*}{ Infrequent } & -0.3881409 & 0.1619659 & -0.0884894 \\
\hline & $(0.000 * * *)$ & $\left(0.016^{* *}\right)$ & $\left(0.000^{* * *}\right)$ \\
\hline \multirow[t]{2}{*}{ Const } & 30.24068 & -24.49031 & -3.100042 \\
\hline & $(0.000 * * *)$ & $(0.003 * * *)$ & $(0.194)$ \\
\hline Pseudo R^2 & 0.5367 & 0.4538 & 0.4184 \\
\hline
\end{tabular}

This table presents in Panel $A$ the median regressions for the repurchase operations of financial firms over the chosen characteristics within the sample. The aim of the estimation is to define evidence of specific fundamental characteristics linked to own stock transaction performance. RTP stands for Relative Transaction Price and and 0 to 5, 0 to 22, 0 to 66, stands for the time interval of the benchmark used in the calculation giving us forward looking relative transaction prices. Heteroskedasticity and autocorrelation robust standard 
errors are used. ${ }^{* * *}{ }^{* *}$ and ${ }^{*}$ show statistical significance at a level of 1, 5 and $10 \%$ respectively.

However, there is one specific improvement. In this model, the relative valuation of firms (proxied by the price-to-earnings ratio) proves to be statistically significant for all timeframes when repurchasing and shows mixed results. For the quarterly RTP's related regression, it shows a negative impact on the capabilities of banks to time the market. However, when reducing the time interval to monthly or weekly, this effect shifts to positive. This variability can be justified to the high level of granularity that the analysis took in it its final form.

\section{Conclusions}

This paper uses firm fundamental characteristics to explain market-timing performance across a different set off firms. It also explains how does trading own stock is influenced if the trades are made on the open market or over the counter. Furthermore, it adds to the literature by plotting how important is a macroeconomic shift event on the firm's ability to time the market and if trading with a lower different frequency is advantageous or not.

For this, we used a broad sample comprising both repurchase and reselling operations, and, transactions made on both, open market as well as over the counter. Here, we focus on 37997 individual own stock transactions from the Portuguese Stock Exchange ranging, between 2005 and 2015.

First, it is fair to say that we confirmed all our proposed hypothesis. More in detail, we find that, different firms indeed present different market timing capabilities. More specifically, on average, smaller firms with lower relative performance when compared to its share value and lower overall results tend to have better market timing capabilities. However, better market timing capabilities are also linked with a better overall efficiency measured by the return-on-assets. This is true for both repurchase and reselling operations. Furthermore, other firm specific characteristics provided ambiguous or non-significant results.

When looking at the overall data, we also found that, trades made after the 2011 Portuguese bailout accounted for better results when compared to the ones made previously to this event.

Moreover, across the scope, infrequent traders were the ones with higher potential of timing the market. This might be since they have more time to assess their trades and that thirdparty investors do not have as much historical information on them to predict their behavior.

At last, but as important, we proved that trading over the counter reduced the market timing ability of firms. This meaning that trades made on the open market are more profitable for firms. 
On a second stage, we analyzed several subsamples within our dataset. First, due to the considerable weight of the financial sector in the Portuguese landscape, we ran a set of equations isolating the financial sector only. Here, we found few differences from our general results. Specifically, we found that for financial sector companies, the higher the relative performance of a firm when compared to its share value, the higher the capabilities of a firm to time the market through repurchases.

Second, we also focused our efforts on the predictive power of firms by running a set of equations using only forward-looking RTP's. Here, we found a high degree of similarity on the results for both the general and the financial data sub-samples. A small difference is associated to our proxy for relative valuation. In this piece of analysis, it showed very small inverse impact. We believe that this change is due to the very high level of granularity in the analysis.

Third, our results focusing on the bailout, market type and frequency proved to be in line with our broad centered benchmark analysis. Curiously, the forward-looking based regression results proved stronger in most of the cases.

On a final remark, our study adds directly to the own stock trading literature by proving the existence of different levels of market timing capabilities across firms with different characteristics. Furthermore, we include both repurchase and reselling data simultaneously from the same set of companies which is not common and to our knowledge as not been done before. Furthermore, our study provides a strong contribute by tackling both own stock trading in the open market and over the counter adding to the OTC related literature as well. At last. But of the upmost importance, we add to the literature on the Portuguese bailout and the impact of major economic shift on the funding opportunity assessment of firms and its impact on own stock trading.

In the future, we aim to focus on the market impact of own stock transactions on the price efficiency and the information content within the prices of stocks.

\section{References}

Asness, C., Hazelkorn, T. and Richardson, S., 2018. Buyback derangement syndrome. The Journal of Portfolio Management, 44(5), pp.50-57. https://doi.org/10.3905/jpm.2018.44.5.050

Bendig, D., Willmann, D., Strese, S. and Brettel, M., 2018. Share repurchases and myopia: Implications on the stock and consumer markets. Journal of Marketing, 82(2), pp.19-41. https://doi.org/10.1509/jm.16.0200

Buffet, W. E. (1984). The Superinvestors of Gram-and-Doddsville. Hermes.

Dittmar, A.K., 2000. Why do firms repurchase stock. The Journal of Business, 73(3), pp.331-355. https://doi.org/10.1086/209646 
Dittmar, A. and Field, L.C., 2015. Can managers time the market? Evidence using repurchase price data. Journal of Financial Economics, 115(2), pp.261-282. https://doi.org/10.1016/j.jfineco.2014.09.007

Drousia, A., Episcopos, A. and Leledakis, G.N., 2018. Market reaction to stock repurchases in Greece. Available at SSRN 3153141. https://doi.org/10.2139/ssrn.3153141

Fenn, G.W. and Liang, N., 1998. Good news and bad news about share repurchases. FEDS paper, (98-4). https://doi.org/10.2139/ssrn.113268

Fernandes, C., Gama, P.M. and Vieira, E., 2016. Does local and Euro area sentiment matter for sovereign debt markets? Evidence from a bailout country. Applied Economics, 48(9), pp.816-834. https://doi.org/10.1080/00036846.2015.1088142

Fu, F. and Huang, S., 2016. The persistence of long-run abnormal returns following stock repurchases and offerings. Management Science, 62(4), pp.964-984. https://doi.org/10.1287/mnsc.2015.2150

Gurnani, S., 2016. The financial crisis in Portugal: austerity in perspective.

Ikenberry, D.L. and Vermaelen, T., 1996. The option to repurchase stock. Financial Management, pp.9-24.

Jensen, M.C., 1986. Agency costs of free cash flow, corporate finance, and takeovers. The American economic review, 76(2), pp.323-329.

Jolls, C., 1996. The role of incentive compensation in explaining the stock-repurchase puzzle. Working paper. Cambridge, Mass.: Harvard Law School.

Kumar, P., Langberg, N., Oded, J. and Sivaramakrishnan, K., 2017. Voluntary disclosure and strategic stock repurchases. Journal of Accounting and Economics, 63(23), pp.207-230. https://doi.org/10.1016/j.jacceco.2017.02.001

Mintz, J., 2007, July 23. Expedia slashes stock buyback plans. Associated Press, Reprinted in USA Today.

Opler, T.C. and Titman, S.D., 1996. Financial distress and capital structure choice. Research in Finance, 14, pp.1-12.

Regulamento da CMVM n . o 5 / 2008 Deveres de Informação (2008). Portugal: CMVM.

Schneider, D.K. and Kohlmeyer III, J.M., 2015. Stock buybacks: Is practice explained by management theory? Journal of Business and Accounting, 8(1), p.64.

Santos, D.D. and Gama, P., 2019. Timing the market with own stock: an extensive analysis with buying and selling evidence. International Journal of Managerial Finance. https://doi.org/10.1108/IJMF-05-2019-0194 
Schneider, D.K. and Kohlmeyer III, J.M., 2015. Stock buybacks: Is practice explained by management theory? Journal of Business and Accounting, 8(1), p.64.

Vermaelen, T., 1981. Common stock repurchases and market signalling: An empirical study. Journal of financial economics, 9(2), pp.139-183. https://doi.org/10.1016/0304$405 \times(81) 90011-8$

Voss, J., 2012. Why do Firms Repurchase Stock? Major Themes in Economics, 14(1), pp.55-75.

\section{Annex}

\subsection{Annex I}

Average daily transaction price calculation procedure:

$$
\text { Average Daily Transaction Price }{ }_{i}=\sum_{j=0}^{n} \frac{\text { operation Volume }_{i, j} \times \text { operation } \text { Price }_{i, j}}{\text { Total Daily Volume Transacted }}
$$

Where: $i$ corresponds to each firm, j identifies a specific trade, repurchase or resell, within each day and each market, both open and over the counter.

\subsection{Annex II}

The Relative Transaction Prices (RTP) acts as a comparing mechanism between the average transaction prices (average resale or repurchase price) received or paid by a firm during a particular period, and a chosen benchmark.

The benchmark price (BP) accounts for daily frequency and is computed considering 5day, 22-day and 66-day length windows:

$$
\text { benchmark }_{a-b}=\sum_{i=a}^{b} \frac{\text { Daily Volume }_{i} \times{\text { Daily Price } \text { Close }_{i}}_{\text {Total Volume }} a-b}{\text { Tol }}
$$

Where $a, b= \pm 5, \pm 22$, or \pm 66 and corresponds to the timeframe (in days) of the estimation window.

To calculate the Benchmark Price we use three distinct windows: centered weekly window, $a=-5$ to $b=+5$; centered monthly window, $a=-22$ to $b=+22$; and, centered quarterly window, $a=-66$ to $b=+66$. $^{1}$

The use of event centered estimation windows helps to account for historical performance of prices and future expectations. Thus, we compute the relative transaction prices as such:

\footnotetext{
${ }^{1}$ Typical number of trading days per week (5-day window), month (22-day window) and quarter (66-day window) accordingly.
} 


$$
\text { Relative Transaction Price }_{i, a-b}=\frac{\text { Average Daily Operation Price }_{i}}{\text { benchmark }_{a-b}}-1
$$

Where the Average Daily Operation Price $i$, stands for the specific transaction day average price (see equation II) and the Benchmark Be-b $_{a-b}$ stands for the average close price in one of the earlier computed benchmarks (see equation 3 ).

We also compute forward looking RTP's by removing the past section of the benchmark windows. This is done as follows:

$$
\text { Relative Transaction Price }(f w d)_{i, 0-b}=\frac{\text { Average Daily Operation } \text { Price }_{i}}{\text { benchmark }_{0-b}}-1
$$

Where, once again the Average Daily Operation Price $(f w d)_{i}$, stands for the specific transaction day average price (see equation 2) and the Benchmark $_{0-b}$ now stands for the average close price in one of the "future" benchmarks: weekly, 0 to +5 , monthly, 0 to +22 , and quarterly, 0 to +66 . 